\title{
Misclassification of recent HIV-1 seroconversion in sub-Saharan Africa using the sensitive/less sensitive technique
}

\author{
Kwabena O Duedu ${ }^{1,2^{*}}$, Anna A Hayford ${ }^{1}$ and Kwamena W Sagoe ${ }^{1}$
}

\begin{abstract}
Background: In resource-limited settings where HIV-1 is endemic, there is a need for simple, inexpensive but effective rapid methods for detecting recent infections and estimating incidence for the purposes of surveillance and management. We sort to determine possible reasons for reported misclassifications of recent HIV-1 seroconversion as determined with the S/LS assay in sub-Saharan Africa.

Findings: We used the modified Determine HIV-1/2 sensitive/less sensitive method for determining recent HIV-1 seroconversion to determine recent infections among ELISA repeat HIV-1 positive samples from blood donors. Furthermore, HIV-1 seropositivity was confirmed using a line immunoassay and the results used to validate the performance of the modified Determine HIV-1/2 S/LS assay. The results confirmed reported misclassifications of recent HIV-1 seroconversion in sub-Saharan Africa. It was noted that, lack of confirmation of HIV-1 seropositivity in suspected cases of HIV-1 contributed to misclassifications.
\end{abstract}

Conclusions: It was concluded that, with confirmation of HIV-1 seropositivity, the modified Determine HIV-1/2 S/LS assay will be a rapid and cost effective method for determining HIV-1 recent infections and estimating incidence in resource-limited settings. The need for detailed studies to validate simple methods for determining recent HIV-1 infections is emphasized.

\section{Findings}

In resource-limited settings where HIV-1 is a burden, the need for reliable incidence surveillance data to help access performance of interventions as well as monitor transmission patterns cannot be overestimated. It is however unfortunate that such settings are coupled with challenges such as equipment and technical expertise. Standard assays, like the 3A11-LS for determining recent HIV infections may be impossible to use in these settings which therefore calls for alternative reliable but cheaper methods to determine recent HIV-1 seroconversion and estimate incidence. Improved laboratory methods for determining recent human immunodeficiency virus type 1 (HIV-1) seroconversion and estimating incidence have been widely reported [1-9]. Improvements in these methods help eliminate the use

\footnotetext{
* Correspondence: koduedu@gmail.com

${ }^{1}$ Clinical Virology Laboratory, Department of Microbiology, University of Ghana Medical School, Accra, Ghana

Full list of author information is available at the end of the article
}

of longitudinal studies, back calculations and other cohort studies which are not only costly but also require consistent follow up of clients and repeated testing which is problematic and much difficult to perform in resource-poor settings [10]. Methods for determining recent HIV-1 infections in single serum samples include minipool (MP) nucleic acid amplification testing (NAT) and individual donation (ID) NAT, detection of p24 antigen and the sensitive/less sensitive (S/LS) method for detecting recent HIV-1 seroconversion [3]. NATs and p24 antigen testing are costly and require specific laboratory equipments to perform. A report on the costeffectiveness of including MP or ID NAT and or p24 antigen testing to blood screening in Ghana found that it was highly costly to perform such tests [11]. The sensitive/less sensitive strategy however seems simpler and 'less costly' to be used in resource-limited settings. Detection of recent seroconversion can provide information on serologically undetected residual infections, monitor transmission trends in a community and also

\section{Ciomed Central}


determine incidence of recent HIV-1 infection. Studies have been performed in some African countries using the S/LS EIA to determine recent HIV-1 seroconversion and estimate incidence [12-15]. It has however been reported that some of these assays give misleading results when used in Sub-Saharan Africa [16].

Recent HIV-1 seroconversion was determined among 76 blood donor plasma samples which tested repeatedly double reactive on the Genescreen Ultra HIV Ag-Ab ELISA which was used at the time of the study for routine HIV screening at the National Public Health \& Reference Laboratory, Accra, Ghana. Of the 76 ELISA repeat reactive samples, 41 tested repeatedly reactive on the Determine ${ }^{\mathrm{TM}}$ HIV-1/2 (Abbott Laboratories, Abbott Park, IL) rapid test. These plasma samples $(\mathrm{n}=41)$ were subsequently taken through the modified Determine S/ LS (Det-S/LS) protocol as described elsewhere [8]. The protocol classified 23 as recent seroconversions and the remaining 18 as longstanding seroconversions. Due to previous reports of misclassifications, we further performed the INNO-LIA ${ }^{\mathrm{TM}}$ confirmatory assay to ascertain the HIV-1 antibody seropositivity on all the initial 76 ELISA double repeat reactive samples. After confirmation, only one of the 23 recent seroconversion samples turned out to be seropositive for HIV-1. It was thus concluded that only this was a true recent HIV-1 seroconversion. All the 35 negative samples as determined by the Determine ${ }^{\mathrm{TM}} \mathrm{HIV}-1 / 2$ rapid test initially were also negative by INNO-LIA ${ }^{\mathrm{TM}}$. All the longstanding seroconversions as determined by the modified Det-S/LS protocol were confirmed as seropositive for HIV-1. On the INNO-LIA ${ }^{\mathrm{TM}}$ strip, the one recent seroconversion showed intense (3+) bands for antibodies to five HIV-1 proteins (sgp120, gp41, p31, p24, \& p17).

For blood donor screening, the use of a very sensitive assay is recommended. These assays though having high sensitivities are not very specific as observed in this study. In the absence of PCR, INNO-LIATM is a good alternative gold method for confirming HIV-1 and HIV2 seropositivity. This is employed in many resource-limited settings where PCR is not available. In this study, the existing systems were used to troubleshoot a local problem. It was observed that, screening samples with the Det-S/LS assay without confirmation was likely to result in an overestimation of recent HIV seroconversion. Any calculations therefore using the misclassified recent data would result in overestimation of incidence of HIV-1 infection. Though fourteen (14) of the initial recent seroconversions were indeterminate on INNO-

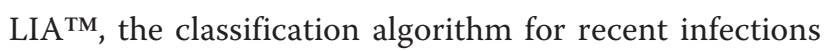
by INNO-LIA as reported by Schupbach and his colleagues [17] could not be used due to absence of clinical information on the blood donor samples used. This classification however is questionable by our results as recent HIV seroconversion did not correspond to faint banding patterns on INNO-LIA ${ }^{\mathrm{TM}}$ as reported. We will therefore like to stress that, incidence estimates calculated with recent seroconversion data obtained using $\mathrm{S} /$ LS and other antibody based recent seroconversion algorithms are likely to be overestimated if HIV seropositivity is not confirmed.

Our results also indicate that, the modified rapid tests may be a good alternative for determining recent HIV-1 seroconversion and estimating incidence in resourcelimited settings. There is therefore a need extensive work into this area of research. Since INNO-LIA ${ }^{\text {TM }}$ is used as a confirmatory test for HIV in Ghana and other settings, there is a need for further studies to characterize seroconversion status of individuals whose antibody status are indeterminate on INNO-LIA ${ }^{\mathrm{TM}}$ and clearly define an algorithm for classifying recent seroconversion as suggested [17]. By this study we propose a simple cost-effective algorithm for determining recent HIV-1 seroconversion in resource limited settings (figure 1). The likely positive samples are taken through the Det-S/ LS protocol as described by Soroka et al [8]. Suspected recent seroconversions are subsequently confirmed for their HIV-1 seropositivity using INNO-LIA ${ }^{\mathrm{TM}}$. The number of tests for INNO-LIA ${ }^{\mathrm{TM}}$ at this stage thus will be reduced as compared to performing INNO-LIA ${ }^{\mathrm{TM}}$ from step 1. In bigger systematic studies, persons classified by this algorithm as false recent seroconvertions may be followed up or a PCR performed where the facility exists to ascertain whether they are really negative for HIV-1 or not.

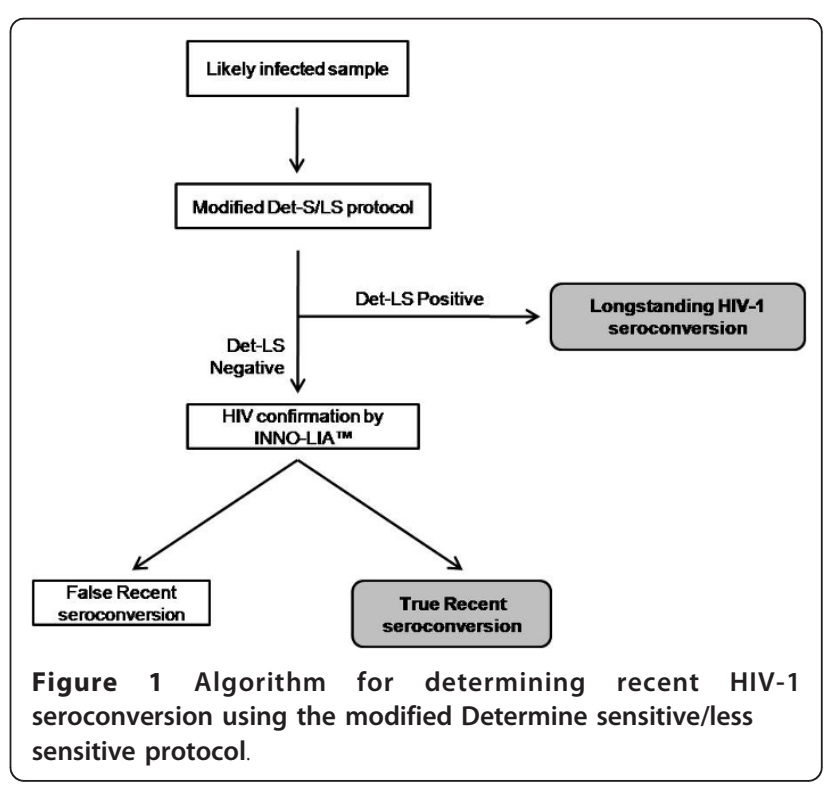




\section{Acknowledgements}

We thank Dr. Parekh S. Bharat of the Division of HIV/AIDS and TB Research, CDC, Atlanta, Georgia, USA for his suggestions and inputs into this study. We also thank the National Blood Service, Korle Bu Teaching Hospital and the 37 Military Hospital Blood Bank for providing samples for this short study. Staff of the National Public Health \& Reference Laboratory, Roland, Michael and co are also appreciated the help in the initial ELISA screening. We also thank Aba, Makafui and Isaac of the Clinical Virology Laboratory, University of Ghana Medical School for their support in the laboratory testing. Support for HIV Test kits was provided by the National AIDS/STIS Control Programme, Ghana.

\section{Author details}

${ }^{1}$ Clinical Virology Laboratory, Department of Microbiology, University of Ghana Medical School, Accra, Ghana. ${ }^{2}$ National Public Health \& Reference Laboratory, Ghana Health Service, Korle-Bu, Accra, Ghana.

\section{Authors' contributions}

KOD and KWCS conceptualized the study. KOD and AAH obtained samples and carried out the tests. KOD drafted the manuscript. KWCS reviewed the manuscript. All authors read and approved the manuscript.

\section{Competing interests}

The authors declare that they have no competing interests.

Received: 25 December 2010 Accepted: 17 April 2011

Published: 17 April 2011

\section{References}

1. Chawla A, Murphy G, Donnelly C, Booth CL, Johnson M, Parry JV, Phillips A, Geretti AM: Human immunodeficiency virus (HIV) antibody avidity testing to identify recent infection in newly diagnosed HIV type 1 (HIV1)-seropositive persons infected with diverse HIV-1 subtypes. J Clin Microbiol 2007, 45: 415-420.

2. Constantine NT, Sill AM, Jack N, Kreisel K, Edwards J, Cafarella T, Smith H, Bartholomew C, Cleghorn FR, Blattner WA: Improved classification of recent HIV-1 infection by employing a two-stage sensitive/less-sensitive test strategy. J Acquir Immune Defic Syndr 2003, 32: 94-103.

3. Janssen RS, Satten GA, Stramer SL, Rawal BD, O'Brien TR, Weiblen BJ, Hecht FM, Jack N, Cleghorn FR, Kahn JO, et al: New testing strategy to detect early HIV-1 infection for use in incidence estimates and for clinical and prevention purposes. JAMA 1998, 280: 42-48.

4. Parekh BS, Kennedy MS, Dobbs T, Pau CP, Byers R, Green T, Hu DJ, Vanichseni S, Young NL, Choopanya K, et al: Quantitative detection of increasing HIV type 1 antibodies after seroconversion: a simple assay for detecting recent HIV infection and estimating incidence. AIDS Res Hum Retroviruses 2002, 18: 295-307.

5. Parekh BS, McDougal JS: Application of laboratory methods for estimation of HIV-1 incidence. Indian J Med Res 2005, 121: 510-518.

6. Rawal BD, Degula A, Lebedeva L, Janssen RS, Hecht FM, Sheppard HW, Busch MP: Development of a new less-sensitive enzyme immunoassay for detection of early HIV-1 infection. J Acquir Immune Defic Syndr 2003, 33: 349-355

7. Sill AM, Kreisel K, Deeds BG, Wilson CM, Constantine NT, Peralta L: Calibration and validation of an oral fluid-based sensitive/less-sensitive assay to distinguish recent from established HIV-1 infections. J Clin Lab Anal 2007, 21: 40-45.

8. Soroka SD, Granade TC, Candal D, Parekh BS: Modification of rapid human immunodeficiency virus (HIV) antibody assay protocols for detecting recent HIV seroconversion. Clin Diagn Lab Immunol 2005, 12: 918-921.

9. Suligoi B, Galli C, Massi M, Di Sora F, Sciandra M, Pezzotti P, Recchia O, Montella F, Sinicco A, Rezza G: Precision and accuracy of a procedure for detecting recent human immunodeficiency virus infections by calculating the antibody avidity index by an automated immunoassaybased method. J Clin Microbiol 2002, 40: 4015-4020.

10. Rutherford GW, Schwarcz SK, McFarland W: Surveillance for incident HIV infection: new technology and new opportunities. J Acquir Immune Defic Syndr 2000, 25(Suppl 2): S115-119.

11. van Hulst M, Sagoe KW, Vermande JE, van der Schaaf IP, van der Tuuk Adriani WP, Torpey K, Ansah J, Mingle JA, Smit Sibinga CT, Postma MJ:
Cost-effectiveness of HIV screening of blood donations in Accra (Ghana). Value Health 2008, 11: 809-819.

12. Karita E, Price M, Hunter E, Chomba E, Allen S, Fei L, Kamali A, Sanders EJ, Anzala O, Katende M, Ketter N: Investigating the utility of the HIV-1 BED capture enzyme immunoassay using cross-sectional and longitudinal seroconverter specimens from Africa. AIDS 2007, 21: 403-408.

13. Moyo S, Bodika SM, Wester WC, Roels TH, Mlotshwa BC, Mphoyakgosi K, Negussie T, Bussmann H, Bile E, Seipone K, et al: Estimation Of HIV incidence in among pregnant women attending antenatal clinics In Botswana in 2005 using serological test for recent seroconversion. 4th IAS Conference on HIV pathogenesis, treatment and prevention Sydney, Australia: International AIDS Society; 2007.

14. Gouws E, Williams BG, Sheppard HW, Enge B, Karim SA: High incidence of HIV-1 in South Africa using a standardized algorithm for recent HIV seroconversion. J Acquir Immune Defic Syndr 2002, 29: 531-535.

15. Riviello ED, Sterling TR, Shepherd B, Fantan T, Makhema J: HIV in the workplace in Botswana: incidence, prevalence, and disease severity. AIDS Res Hum Retroviruses 2007, 23: 1453-1460.

16. Sakarovitch C, Rouet F, Murphy G, Minga AK, Alioum A, Dabis F, Costagliola D, Salamon R, Parry JV, Barin F: Do tests devised to detect recent HIV-1 infection provide reliable estimates of incidence in Africa? J Acquir Immune Defic Syndr 2007, 45: 115-122.

17. Schupbach J, Gebhardt MD, Tomasik Z, Niederhauser C, Yerly S, Burgisser P, Matter L, Gorgievski M, Dubs R, Schultze D, et al: Assessment of recent HIV-1 infection by a line immunoassay for HIV-1/2 confirmation. PLoS Med 2007, 4: e343.

\section{doi:10.1186/1743-422X-8-176}

Cite this article as: Duedu et al:: Misclassification of recent HIV-1 seroconversion in sub-Saharan Africa using the sensitive/less sensitive technique. Virology Journal 2011 8:176.

\section{Submit your next manuscript to BioMed Central and take full advantage of:}

- Convenient online submission

- Thorough peer review

- No space constraints or color figure charges

- Immediate publication on acceptance

- Inclusion in PubMed, CAS, Scopus and Google Scholar

- Research which is freely available for redistribution

Submit your manuscript a www.biomedcentral.com/submit
Biomed Central 